\title{
Improvement of fatigue properties in cast aluminum A356 by warm deformation
}

\section{DOI:}

10.1002/9781119041498.ch1

Link to publication record in Manchester Research Explorer

\section{Citation for published version (APA):}

Maijer, D. M., Roy, M., \& Nadot, Y. (2014). Improvement of fatigue properties in cast aluminum A356 by warm deformation. In MS\&T 2014: Fatigue of Materials III: Advances and Emergences in Understanding https://doi.org/10.1002/9781119041498.ch1

\section{Published in:}

MS\&T 2014: Fatigue of Materials III: Advances and Emergences in Understanding

\section{Citing this paper}

Please note that where the full-text provided on Manchester Research Explorer is the Author Accepted Manuscript or Proof version this may differ from the final Published version. If citing, it is advised that you check and use the publisher's definitive version.

\section{General rights}

Copyright and moral rights for the publications made accessible in the Research Explorer are retained by the authors and/or other copyright owners and it is a condition of accessing publications that users recognise and abide by the legal requirements associated with these rights.

\section{Takedown policy}

If you believe that this document breaches copyright please refer to the University of Manchester's Takedown Procedures [http://man.ac.uk/04Y6Bo] or contact uml.scholarlycommunications@manchester.ac.uk providing relevant details, so we can investigate your claim.

\section{OPEN ACCESS}




\title{
IMPROVEMENT OF FATIGUE PROPERTIES OF CAST ALUMINUM A356 BY WARM DEFORMATION
}

\author{
M. J. Roy ${ }^{1}$, D. M. Maijer ${ }^{2}$, Y. Nadot ${ }^{3}$ \\ ${ }^{1}$ The University of Manchester \\ School of Mechanical, Aerospace and Civil Engineering \\ Sackville Street Building, Manchester \\ United Kingdom, M13 9PL \\ ${ }^{2}$ The University of British Columbia \\ Department of Materials Engineering \\ 309-6350 Stores Road, Vancouver, BC \\ Canada, V6T 1Z4 \\ ${ }^{3}$ Institut PPRIME - CNRS \\ Université de Poitiers \\ ENSMA - UPR 3346 - \\ Départment Mécanique des Matériaux \\ Téléport 2 - 1 Avenue Clément Ader - BP \\ 4019 - 86961 FUTUROSCOPE CHASSENEUIL \\ Cedex - France
}

Keywords: $\quad$ A356, Fatigue, Flow forming

\begin{abstract}
Aluminum foundry alloys such as A356 are used extensively in applications where high cycle fatigue (HCF) resilience is a key design consideration. Fully reversed, multiaxial HCF studies on this alloy in the T6 condition have shown that endurance limits are governed by maximum principal stress and driven by crack propagation as opposed to initiation. In light of these fatigue characteristics, it has been found that warm deformation imparted via flow forming prior to heat treatment improves the fatigue resilience by upwards of $30 \%$ depending on the degree of deformation. The fatigue performance improvement has been attributed to eutectic particle size and morphology changes and potential recrystallisation of the primary phases. This hypothesis is supported by extensive particle characterisation and preliminary EBSD results.
\end{abstract}




\section{Introduction}

Aluminum castings are employed by many different industries to provide lightweight, near net-shape components. However, these components may be defective due to inherent porosity and microstructure inhomogeneity. Standard forging operations can mitigate some of these issues, but are expensive in terms of tooling and operation costs. A lower cost and more flexible alternative for hollow axisymmetric components is rotary forming. This process consists of fixing the workpiece on a rotating mandrel followed by local deformation with a roller or other shaping tool which moved axially along the component. This introduces a highly localized plastic zone which reduces the wall thickness and elongates the component. Rotary forming is often commercially referred to as spinning, shear forming or flow forming depending on the degree of deformation imparted to the workpiece [1].

A356 (Al-7Si-0.3Mg) is a common aluminum casting alloy consisting of a dendritic structure comprised of $\alpha$-Al surrounded by Sirich eutectic (Fig. 1) which typically undergoes a T6 heat treatment after casting. High cycle fatigue (HCF) lives within this material are typically decided by porosity and large eutectic particles or other inclusions remaining post-heat treatment [2]. Previous work [3, 4] which investigated the multiaxial fatigue properties of this alloy have indicated that fatigue life limiting defects are quite large, upwards of $400 \mu \mathrm{m}$ as crack propagation dominates HCF behaviour. Outside of pure torsion, the maximum principal stress is the primary driver of crack propagation which indicates that $\mathrm{S}-\mathrm{N}$ data tabulated from uniaxial fatigue testing may be employed to gauge multiaxial performance.

\section{Experiment details}

Two sources of flow formed A356 were used to characterize the effects on fatigue resilience due to processing. Material that was commercially formed and heat treated to the T6 condition was received as unmachined, low pressure die cast wheel blanks from a North 
American automotive wheel manufacturer, referred to further as 'commercial'. The second source of material was modified as-cast (AC) wheel blanks from the same supplier. A portion of these blanks were T6 treated immediately and the remainder processed with a purpose-built experimental rotary forming apparatus, referred to further as 'experimental'. In both cases, the material was deformed at a target temperature of $350^{\circ} \mathrm{C}$, with the commercial material experiencing heavy deformation (upwards of $50 \%$ wall thickness reduction) and the experimental material undergoing light deformation (approximately 10\% wall thickness reduction). All material in this study was subjected to a standard T6 heat treatment consisting of solutionizing at $540^{\circ} \mathrm{C}$ for 3 hours, followed by a $60^{\circ} \mathrm{C}$ water quench and concluded with an artificial aging period at $150^{\circ} \mathrm{C}$ for 3 hours immediately after quenching. The effect of deformation on the microstructure showed either a light deformation of the dendrite cells in the direction of forming or a complete loss of dendritic structure. The former microstructure was predominant in the experimental material, while the commercial material exhibited a range of microstructure between the two conditions.

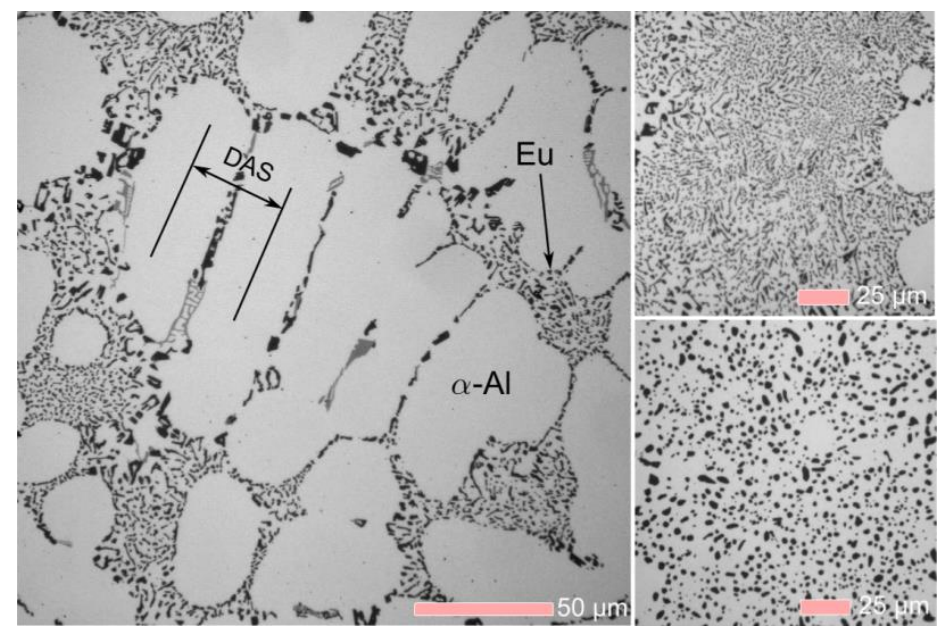

Figure 1. As-cast A356 microstructure (left), as-cast eutectic (top right) and eutectic post T6-treatment (bottom right). 
Table 1. Source, condition and quantity employed in fatigue study.

\begin{tabular}{lll}
\hline Source & Condition & Quantity \\
& $\mathrm{AC}$ & 55 \\
\cline { 2 - 3 } & & $4(\mathrm{~A})$ \\
Comm. & Formed & $4(\mathrm{AD})$ \\
& & $4(\mathrm{H})$ \\
& & 15 \\
\hline \multirow{2}{*}{ Exp. } & AC & 12 \\
\cline { 2 - 3 } & Formed & \\
\hline
\end{tabular}

Post heat-treatment, hour-glass uniaxial fatigue specimens were extracted with geometry conforming to ASTM E606. The commericallyformed material had specimens extracted from different locations within the blank, corresponding to heavy and light deformation in the axial (A and $\mathrm{AD}$, respectively) and hoop direction ( $\mathrm{H}$ and $\mathrm{HD}$, respectively). Samples from the experimentally-formed material were drawn solely in the axial direction from the most heavily deformed region of the component. As cast, undeformed material (AC) corresponding to both blank configurations had specimens extracted from equivalent locations. See Table 1 for specimen counts, and Fig. 2 for specimen extraction points.

All specimens were run-out tested to failure under fully reversed conditions $(\mathrm{R}=-1)$ with a Sonntag eccentric fatigue machine at $33 \mathrm{~Hz}$, with load amplitudes targeting the mid to high cycle $\left(10^{5}-10^{6}\right)$ fatigue regime. The microstructure was analyzed to ascertain effects of forming using microindentation, optical and scanning electron microscopy (OM and SEM) techniques.

\section{Fatigue Results}

Fig. 3 demonstrates S-N data for undeformed (I commercial and II experimental) versus flowformed (III commercial and IV 
experimental) material. The improvement in endurance has been quantified by fitting Basquin relationships $(b=0.17)$ through results from each sample type and source via non-linear least-squares (Table 2). As a general assessment of how the endurance limit improved, the commercial and experimental S-N data was combined and fitted. The endurance limit(sf) evaluated at 106 cycles using this relationship showed an provement of $75 \mathrm{MPa}$ for undeformed material versus 107 MPa for flow-formed or an improvement of $30 \%$.

Separate analysis on each of the flow-formed specimen streams (experimental vs. commercial) was also conducted. There was little difference in fatigue limit noted for each of the commercial specimen orientations (AD vs. HD) or degree of deformation (A vs. AD and $\mathrm{H}$ vs. HD). At least four of the A specimens had fatigue lives that meet or exceed the AD specimens at the same load amplitude. One HD specimen failed prior to an $\mathrm{H}$ specimen at a load amplitude of $\sigma^{\mathrm{a}}=110 \mathrm{MPa}$ with the opposite occurring at $\sigma^{\mathrm{a}}=125 \mathrm{MPa}$. Therefore, little conclusions can be drawn regarding the effect of orientation and deformation within the scatter of S-N data. Overall, the commercial material showed a 33\% increase in fatigue limit over undeformed material. The experimental material showed approximately the same fatigue lives as the specimens taken from the commercial material for loading amplitudes between 110 and $120 \mathrm{MPa}$, and other specimens had lives falling within two orders of magnitude of the commercial specimens with identical $\sigma^{\mathrm{a}}$. The undeformed experimental material demonstrated significantly higher fatigue limits than the undeformed commercial material (72 vs. $84 \mathrm{MPa}$, respectively), which accounts for the reason why experimental material only showed a $19 \%$ increase in fatigue limit due to forming. This is likely due to a specimen size effect; larger specimens have an increased number of defects which could affect fatigue limits.

Overall, flow-forming has been shown to significantly improve the fatigue properties of A356. Departure from fitted Basquin relationships, quantified by both $\mathrm{R}^{2}$ and RMSE was diminished for both sources of material. As the improvement in fatigue limits for commercial material was appreciably higher than the experimental material, 
increased deformation and resulting porosity mitigation is the principal reason.

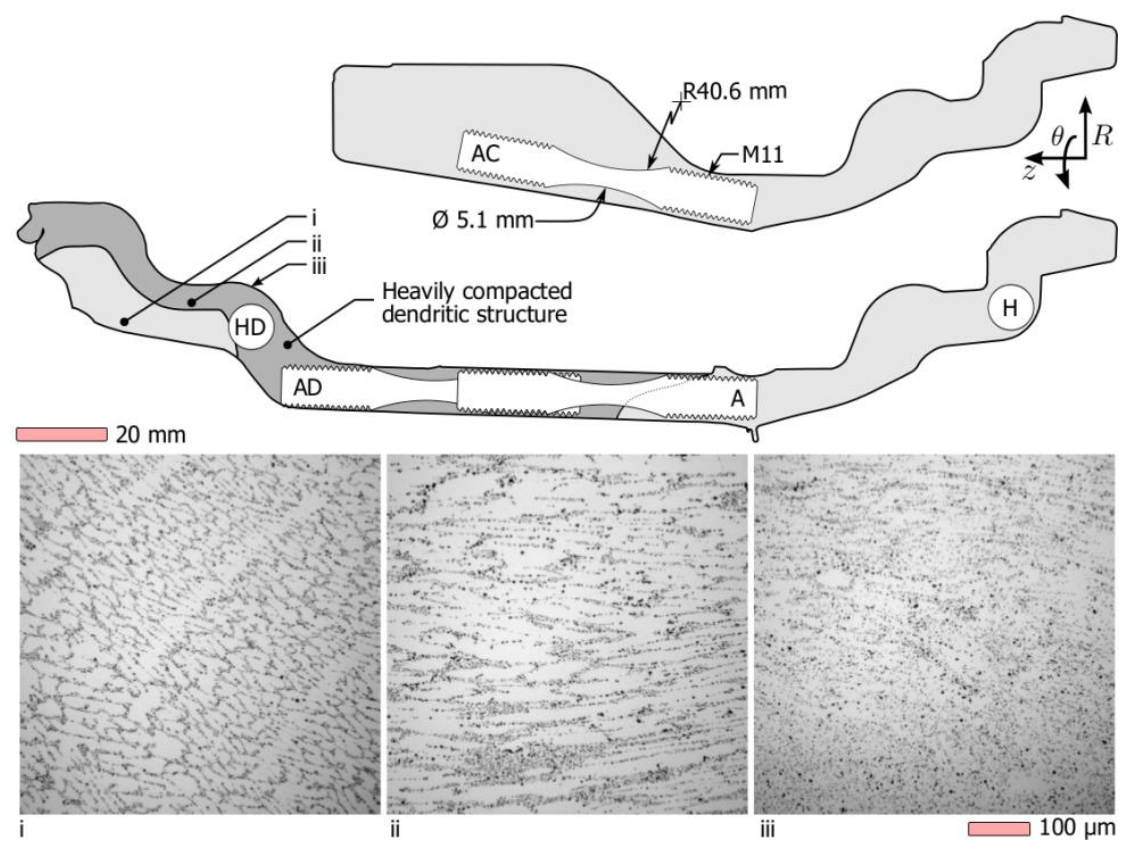

Figure 2. Pre and post deformed geometry of commercial specimens. Micrographs correspond to locations in the diagram above 


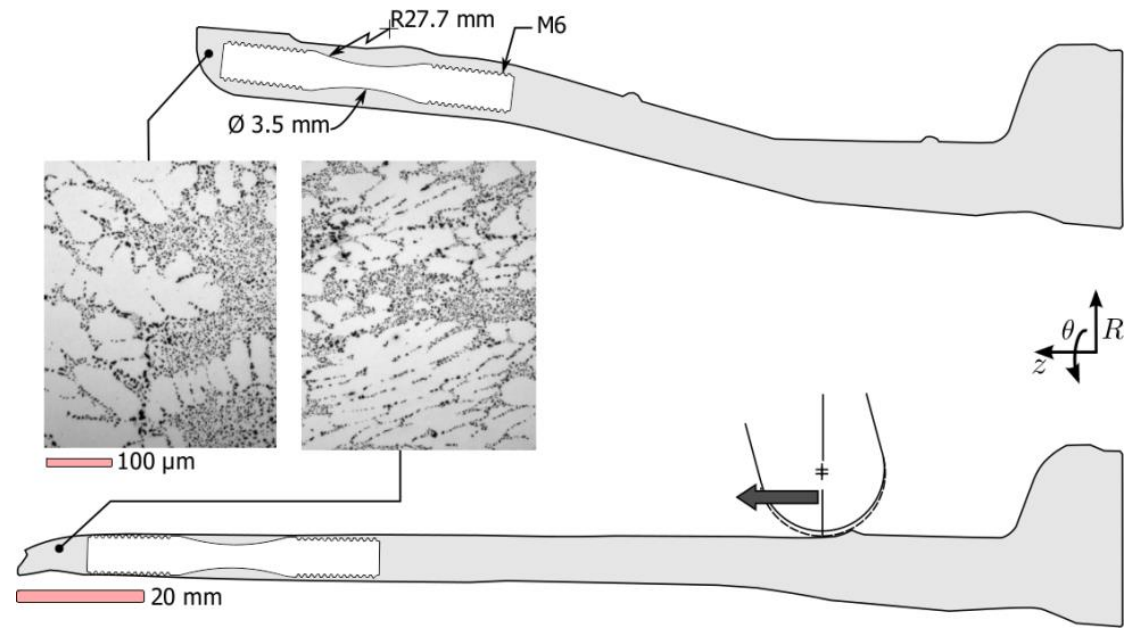

Figure 3. Pre and post deformed geometry of experimental specimens. Micrographs correspond to locations in the diagram above.

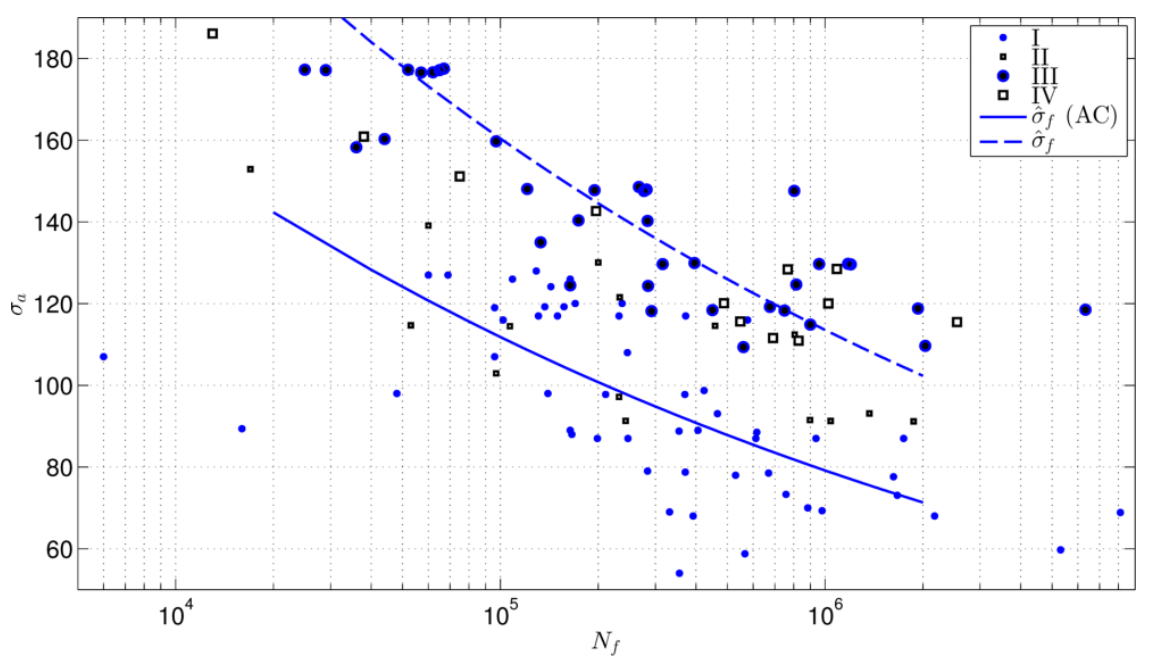

Figure 4. AC-T6 versus formed-T6 fatigue results. 
Table 2. AC-T6 versus formed-T6 Basquin relationships

\begin{tabular}{llllll}
\hline $\begin{array}{l}\text { Fig. } \\
\text { Series }\end{array}$ & Conditions & $\begin{array}{l}\boldsymbol{\sigma}_{\mathbf{f}} \\
(\mathbf{M P a})\end{array}$ & $\mathbf{R}^{2}$ & $\mathbf{R M S E}$ & $\boldsymbol{\sigma}_{\mathbf{f}} \mid \mathbf{1 0}^{\mathbf{6}}$ \\
\hline I & AC-T6 & 851.14 & 0.7441 & 21.69 & 72.25 \\
\cline { 2 - 6 } III & $\begin{array}{l}\text { Commercially } \\
\text { formed-T6 }\end{array}$ & 1270.02 & 0.8629 & 166.7 & 107.80 \\
\hline II & AC-T6 & 985.49 & 0.8322 & 15.90 & 83.64 \\
\cline { 2 - 6 } IV & Exp. formed- & 1215.16 & 0.8850 & 17.32 & 103.15 \\
& T6 & & & & \\
\hline I \& II & AC-T6 & 880.56 & 0.7454 & 21.49 & 74.75 \\
\cline { 2 - 6 } III \& IV & formed-T6 & 1256.7 & 0.8703 & 17.04 & 106.67 \\
\hline
\end{tabular}

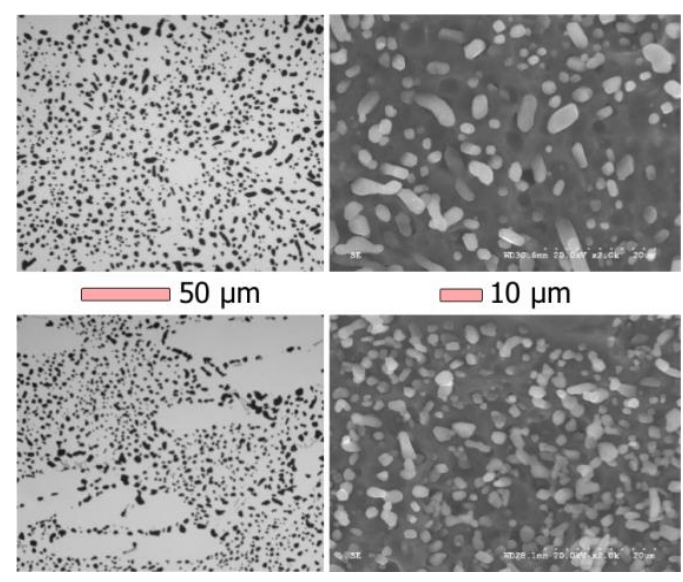

Figure 5. Undeformed A356-T6 eutectic particles (top) versus deformed (bottom) 


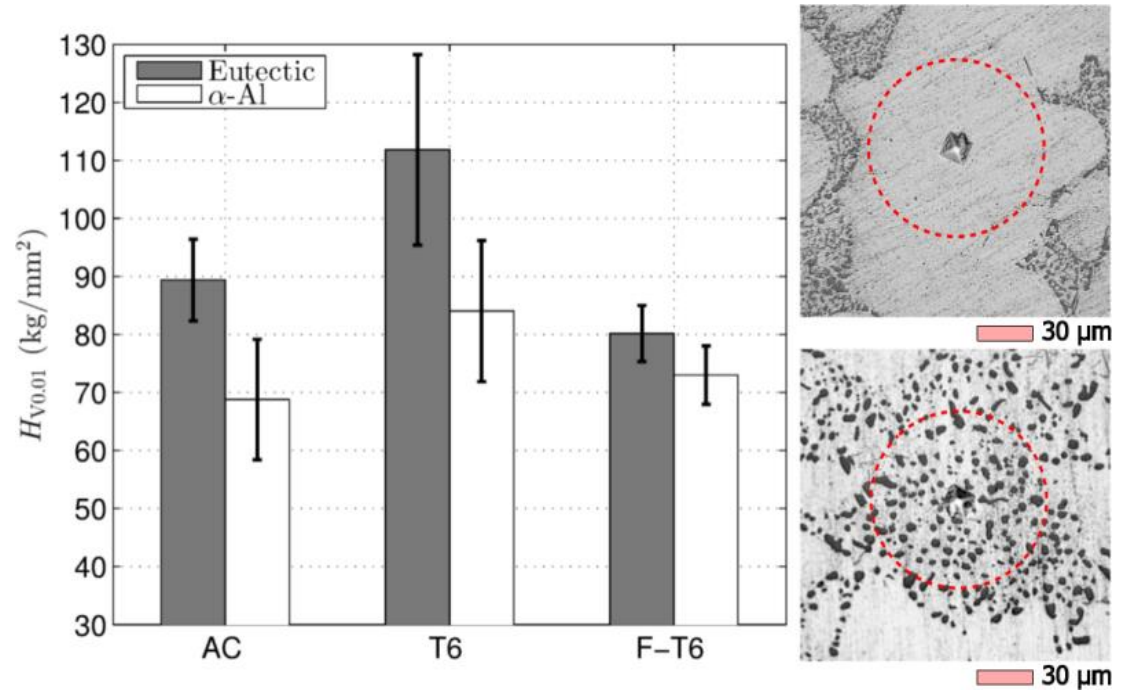

Figure 6. Phase-specific microhardness measurements of untempered $(\mathrm{AC})$, undeformed-T6 (T6) and deformed-T6 (F-T6)

\section{Summary}

In the case of rotary formed material, a comparison of runout $\mathrm{S}-\mathrm{N}$ data showed the overall HCF endurance limit was improved by $30 \%$ over undeformed material. The commercially processed material showed a $33 \%$ increase in endurance limit, and the experimentally flow formed material showed a $19 \%$ improvement. As the commercially processed material was deformed to a much higher extent than the experimentally processed material, this implies that increased levels of rotary forming improves the fatigue properties of the material accordingly. The cause for this increase is primarily attributed to the mitigation of porosity. Secondary causes may be attributed to the refinement of eutectic particles induced by processing, which in turn slows crack propagation and potential recrystallization. 


\section{References}

1. O. Music, J.M. Allwood, K. Kawai, "A review of the mechanics of metal spinning", Journal of Materials Processing Technology 210 (2010) 3-23

2. D.L. McDowell, K. Gall, M.F. Horstmeyer, J. Fan, "Microstructure-based fatigue modeling fo cast A356-T6 alloy", Engineering Fracture Mechanics 70 (2003) 49-80.

3. M.J. Roy, Y. Nadot, C. Nadot-Martin, P.-G. Bardin, D.M. Maijer, "Multiaxial Kitigawa analysis of A356-T6", International Journal of Fatigue, 33 (2011), 823-832.

4. M. Roy, Y. Nadot, D.M. Maijer and G. Benoit, "Multiaxial fatigue behavior of A356-T6", Fatigue \& Fracture of Engineering Materials \& Structures, 35 (2012), 1148-1159.

5. Q.G. Wang, D. Apelian, D.A. Lados, "Microstructural Effects on the Tensile and Fracture Behaviour of Aluminum Casting Alloys A356/A357", Metallurgical and Materials Transactions A 34A (2003) 2887-2899. 